\title{
You're Not the One: Treating Subjects Co-infected with Hepatitis $C$ Genotypes 2 and 3 and Human Immunodeficiency Virus
}

\author{
Brian L. Pearlman • Tanna H. Lim
}

Received: 22 June 2014/ Accepted: 25 June 2014/Published online: 8 July 2014

(C) Springer Science+Business Media New York 2014

Since the molecular identification of the hepatitis $\mathrm{C}$ virus (HCV) was first publicly disclosed in 1988 [1], the understanding of the biology of the virus and of antiviral treatment strategies has evolved rapidly. The HCV virus has been classified into seven strains based on viral genotype. Of these, genotype 1 is the predominant isolate in the USA; due to historically poor cure rates using conventional interferon (IFN)-based therapies, more efficacious and safer antiviral therapies have been developed. As a result, substantial gains in the cure rates (nondetectable viremia with $<1 \%$ recurrence over 2 decades of prospective follow-up) for genotype 1 infection have been reported, with sustained virologic response (SVR) rates (undetectable serum HCV RNA with a sensitive assay 12 weeks after therapy completion) $>90 \%[2,3]$.

In the past, genotypes 2 and 3 were considered relatively easy-to-treat with SVR rates up to $80 \%$ with IFN-based therapy for 12-24 weeks [4]. Due to this ease of therapy, these genotypes have been somewhat ignored as therapeutic targets in the past five years. While more recent studies have reported promising results incorporating direct-acting antiviral agents such as sofosbuvir for treating

B. L. Pearlman $(\bowtie)$

Center for Hepatitis C, Atlanta Medical Center, 285 Boulevard NE Suite 525, Atlanta, GA 30312, USA

e-mail: brianpearlman@ hotmail.com

B. L. Pearlman · T. H. Lim

Medical College of Georgia, Atlanta, GA, USA

B. L. Pearlman

Emory School of Medicine, Atlanta, GA, USA

T. H. Lim

Department of Graduate Medical Education, Atlanta Medical Center, Atlanta, GA, USA genotype 2 and 3 infections [5], because of cost, many patients continue to have very limited access to these new therapies.

Co-infection with HCV and the human immunodeficiency virus (HIV) occurs in approximately $20-30 \%$ of patients infected with HIV [6]. This is a significant concern since dually infected patients have relatively faster progression to cirrhosis compared with those with HCV monoinfection. Furthermore, even with virologic suppression with antiretroviral therapy (ART), co-infected patients have higher rates of hepatic decompensation and other severe hepatic complications [7]. In addition to inferior outcomes, treatment of co-infected patients is more difficult due to drug-drug interactions with ART. SVR rates $\sim 60-75 \%$ were reported for peginterferon therapy of genotype 2-3 co-infected subjects [4]. Clinical stability while receiving ART regimens with relatively preserved CD4+ immunity is recommended prior to initiating hepatitis $\mathrm{C}$ therapy in co-infected subjects.

In co-infected subjects, few data are available addressing the optimal duration of treatment, especially with genotype 2 and 3 infections. Older guidelines published by the American Association for the Study of Liver Diseases (AASLD) recommend treatment with peginterferon and ribavirin in co-infected patients for 48 weeks, regardless of genotype [8]. Yet, the European AIDS Clinical Society does allow for shortened duration therapy in patients who achieve rapid virologic response (RVR)-subjects in whom the virus is undetected in serum by week 4 of treatment [9]. Only a few studies have evaluated $<48$-week therapy durations in this population (Table 1).

Based on the PHOTON-1 study [14], the most recent AASLD-IDSA (Infectious Diseases Society of America) Guidelines recommend 12 and 24 weeks of sofosbuvir plus ribavirin without interferon for genotype 2- and 
Table 1 Summary of treatment truncation studies for HIV-HCV coinfection, genotypes $2+3$

\begin{tabular}{|c|c|c|c|c|c|}
\hline Reference & $\begin{array}{l}\text { Genotype(s) } \\
\text { studied }\end{array}$ & Trial design & $n$ & $\begin{array}{l}\text { Duration if RVR } \\
\text { achieved (weeks) }\end{array}$ & $\begin{array}{l}\text { SVR rate with } \\
\text { short duration }(\%)\end{array}$ \\
\hline Mandorfer et al. [10] & $2 / 3$ & Retrospective & 84 & 24 & 93 \\
\hline Mira et al. [11] & $2 / 3$ & Retrospective & $27 *$ & 24 & $100 *$ \\
\hline Martin-Carbonero et al. [12] & $2 / 3$ & Retrospective & $46^{*}$ & 24 & $89^{*}$ \\
\hline Rivero-Juarez et al. [13] & 3 & Prospective & $74 *$ & 24 & $81^{*}$ \\
\hline
\end{tabular}

$R V R$ rapid virologic response, $S V R$ sustained virologic response

* Genotype 3

3- co-infected subjects, respectively, specifically excluding regimens based solely on peginterferon and ribavirin [15].

In this issue of Digestive Diseases and Sciences, Win et al. [16] report the results of a single-center experience using response-guided therapy (RGT) for the treatment of HCV genotype 2 or 3 HIV co-infected subjects. All subjects were treated with peginterferon and weight-based ribavirin. In keeping with the principles of RGT, therapy duration was dependent on the rapidity of viral suppression [17]. Those with undetectable virus by treatment weeks 4 , 8 , and 12 continued antiviral therapy for a total duration of 24,36 , and 48 weeks, respectively. Impressively, of the 23 patients who initiated this regimen, only one required the full 48 weeks of therapy, with $100 \%$ of patients achieving SVR using the RGT strategy.

Although Win et al.'s results appear superior to comparable studies of similar populations, with one reporting an SVR rate of only $44 \%$ [18], the study should provide hope that with proper support systems in place, along with highly motivated subjects, the cure rates can be substantially higher than have been published in the past. Nonetheless, several caveats apply to the approach by Win et al., including the study's single-center database, its retrospective design, and its very small sample size. The subgroup of patients with advanced liver disease, particularly cirrhosis, is even smaller and thus even more difficult from which to draw conclusions about therapy duration. Many questions and unknowns remain for co-infected patients with genotypes 2 and 3 such as extrapolation to a non white population or if the population studies by Win et al. were artificially enriched in subjects with genotype IL-28B, which is associated with enhanced response to IFN-based therapies. Finally, if a patient responds very quickly, could therapy duration be abbreviated even further?

In summary, although peginterferon-ribavirin may not be the ideal therapy because of its associated adverse effects, it still remains a cornerstone of hepatitis C therapy, particularly for subjects infected with genotypes 2 and 3 who are HIV co-infected and have no access to more expensive direct antiviral medications. Although newer therapies may prove to be highly effective, their current cost is prohibitive in many parts of the world where these genotypes are more common. In properly selected subjects, while cure rates can be improved significantly, there is still much to learn about the treatment nuances leading to success or failure, particularly in co-infected patients. While our knowledge has increased considerably, much more is yet to be learned.

\section{References}

1. Houghton M. Discovery of the hepatitis C virus. Liver Int. 2009;29:82-88. doi:10.1111/j.1478-3231.2008.01925.x.

2. Afdhal N, Reddy KR, Nelson DR, et al. Ledipasvir and sofosbuvir for untreated HCV genotype 1 infection. $N$ Engl J Med. 2014:370:1889-1898.

3. Poordad F, Hezode C, Trinh R, et al. ABT-450/r-ombitasvir and dasabuvir with ribavirin for hepatitis $\mathrm{C}$ with cirrhosis. $N$ Engl J Med. 2014;370:1973-1982.

4. Brown K, LaBrie M, Coffin CS. Treatment of genotype 2 and genotype 3 hepatitis $\mathrm{C}$ virus (HCV) infection in human immunodeficiency virus positive patients. Curr HIV/AIDS Rep. 2013;10:420-427.

5. Zeuzem S, Dusheiko GM, Salupere R, et al. Sofosbuvir and ribavirin in HCV genotypes 2 and 3. N Eng J Med. 2014. doi:10. 1056/NEJMoa1316145.

6. Rockstroh JK, Spengler U. HIV and hepatitis C virus co-infection. Lancet Infect Dis. 2004;4:437-444.

7. Re VL III, Kallan MJ, Tate JP, et al. Hepatic decompensation in antiretroviral-treated patients co-infected with HIV and hepatitis $\mathrm{C}$ virus compared with hepatitis $\mathrm{C}$ virus-noninfected patients. Ann Intern Med. 2014;160:369-379.

8. Ghany MG, Strader DB, Thomas DL, et al. Diagnosis, management, and treatment of hepatitis C: an update. Hepatology. 2009;49:1335-1374. doi:10.1002/hep.22759.

9. European AIDS Clinical Society Guidelines Version 7.0. http:// eacsociety.org/Portals/0/Guidelines_Online_131014.pdf. Accessed May 22, 2014.

10. Martin-Carbonero L, Nuñez M, Mariño A, et al. Undetectable hepatitis C virus RNA at week 4 as predictor of sustained virological response in HIV patients with chronic hepatitis C. AIDS. 2008;22:15-21.

11. Mira JA, Valera-Bestard B, Arizcorreta-Yarza A, et al. Rapid virological response at week 4 predicts response to pegylated interferon plus ribavirin among HIV/HCV-coinfected patients. Antivir Ther. 2007;12:523-529.

12. Mandorfer M, Neukam K, Reiberger T, et al. The impact of interleukin 28B rs12979860 single nucleotide polymorphism and liver fibrosis stage on response-guided therapy in $\mathrm{HIV} / \mathrm{HCV}$-coinfected 
patients. AIDS. 2013;27:2707-2714. doi:10.1097/01.aids. 0000432460.44593.ef.

13. Rivero-Juarez A, López-Cortés LF, Camacho A, et al. A 24-week treatment strategy with pegylated interferon/ribavirin in HIV/ hepatitis $\mathrm{C}$ virus genotype 3-coinfected patients who achieved a rapid virologic response results in a high sustained virologic response rate. Clin Infect Dis. 2014;58:130-133. doi:10.1093/cid/ cit653.

14. Sulkowski MS, Rodriguez-Torres M, Lalezari JP, et al. All-oral therapy with Sofosbuvir plus ribavirin for the treatment of HCV genotype 1,2, and 3 infection in patients co-infected with HIV (PHOTON-1). 64th Annual Meeting of the American Association for the Study of Liver Diseases (AASLD 2013). Washington, DC, November 1-5, 2013. Abstract 212.

15. American Association for the Study of Liver Diseases (AASLD) and Infectious Diseases Society of America (IDSA). Recommendations for testing, managing, and treating hepatitis C. http://www.hcvgui delines.org/full-report/initial-treatment-hcv-infection-patientsstarting-treatment. Revised March 21, 2014. Accessed June 1, 2014.

16. Win LL, James P, Wong DK. Response-guided therapy for hepatitis C genotype 2 and 3 in those with HIV coinfection. Dig Dis Sci. 2014. doi:10.1007/s10620-014-3211-6.

17. James PD, Wong DK. Optimizing hepatitis C therapy in HIV hepatitis $\mathrm{C}$ virus $(\mathrm{HCV})$ coinfected patients: analysis of $\mathrm{HCV}$ viral kinetics on treatment. Can J Infect Dis Med Microbiol. 2012;23:31-35.

18. Ioannou GN, Scott JD, Yang Y, et al. Rates and predictors of response to antiviral treatment for hepatitis $\mathrm{C}$ virus in $\mathrm{HIV} / \mathrm{HCV}$ co-infection in a nationwide study of 619 patients. Aliment Pharmacol Ther. 2013;38:1373-1384. 